\title{
Hypothyroidism and early pregnancy loss: an overview
}

\section{Puja Verma*, Dipti Roy}

Department of Obstetrics and Gynaecology, Nalanda Medical College and Hospital, Patna, Bihar, India

Received: 30 September 2020

Accepted: 05 November 2020

\author{
*Correspondence: \\ Dr. Puja Verma, \\ E-mail: drvermapuja@gmail.com
}

Copyright: (c) the author(s), publisher and licensee Medip Academy. This is an open-access article distributed under the terms of the Creative Commons Attribution Non-Commercial License, which permits unrestricted non-commercial use, distribution, and reproduction in any medium, provided the original work is properly cited.

\begin{abstract}
Background: Thyroid disorders are associated with adverse pregnancy outcomes and can lead to spontaneous miscarriages.

Methods: One hundred and four women with early pregnancy loss were enrolled in this study and thyroid profile was done. Thyroid status of women was established on the basis of standard cut-off levels. Prevalence of hypothyroidism (both overt and subclinical) was calculated.

Results: The mean TSH level was $2.3 \pm 1.3 \mu \mathrm{IU} / 1$. Twenty two women had increased TSH level $(>2.5 \mu \mathrm{IU} / \mathrm{l})$ accounting to $21.15 \%$ of total women and rest $78.84 \%$ women were euthyroid. $15.38 \%$ of women presenting with early pregnancy loss were overt hypothyroid and $5.76 \%$ of women had subclinical hypothyroidism. The mean TSH level in hypothyroid group was $4.9 \pm 2.1$.

Conclusions: Hypothyroidism if untreated can lead to first trimester abortions. All pregnant women should be screened for thyroid disorders in their first visit and treatment should be started at the earliest.
\end{abstract}

Keywords: Early pregnancy loss, Hypothyroidism, TSH

\section{INTRODUCTION}

Thyroid disorders are associated with adverse pregnancy outcomes. They can lead to spontaneous miscarriages. Miscarriage or spontaneous abortion is defined as expulsion or extraction of the embryo or foetus weighing $<500 \mathrm{~g}$, or before 20-22 weeks of gestation. It is the most common complication of early pregnancy. ${ }^{1}$ The various causes of early pregnancy loss are genetic, anatomic factors, autoimmune disorders, endocrine dysfunction, thrombophilia, life style factors, maternal infections and may be idiopathic.

Thyroid disorders constitute one of the most common endocrine disorders in pregnancy. ${ }^{2}$ Pregnancy is associated with profound modifications in the regulation of thyroid function. These changes are the result of various factors like an increase of thyroxine-binding globulin (TBG) due to elevated estrogen and human chorionic gonadotropin (hCG), increased renal losses of iodine due to increased glomerular filtration rate, modifications in the peripheral metabolism of maternal thyroid hormones, and modification in iodine transfer to the placenta. ${ }^{3}$

Women with thyroid dysfunction both overt and subclinical are at increased risk of pregnancy-related complications such as threatened abortion, preeclampsia, preterm labour, placental abruption, and postpartum haemorrhage. Foetal complications include first-trimester spontaneous abortions, low-birth-weight babies, preterm delivery, intrauterine growth retardation, high rates of still birth and neonatal deaths, neonatal hyperbilirubinemia, higher incidence of neonatal hypothyroidism, and increased perinatal mortality. ${ }^{4}$

Thyroid disorders can be either hypothyroidism or hyperthyroidism. Euthyroid women are defined as those having normal TSH $(0.1-2.5 \mu \mathrm{IU} / \mathrm{l})$ in first trimester. Subclinical hypothyroidism is defined as high TSH $(>3.0$ $\mu \mathrm{IU} / 1)$ in the presence of normal levels of Free T4 (0.8-2.0 
$\mathrm{ng} / \mathrm{dl})$. Overt hypothyroidism is defined as high TSH $(>3.0$ $\mu \mathrm{IU} / \mathrm{l})$ with low Free T4 $(<0.8 \mathrm{ng} / \mathrm{dl})$. Subclinical hyperthyroidism is defined as low serum TSH $(<0.2 \mu \mathrm{IU} / \mathrm{l})$ concentration with normal Free T4 $(0.8-2.0 \mathrm{ng} / \mathrm{dl})$ and overt hyperthyroidism is defined as with high Free T4 $(>2.0 \mathrm{ng} / \mathrm{dl})$ with decreased TSH $(<0.2 \mu \mathrm{IU} / \mathrm{l})$.

The aim of this study was to determine the prevalence of hypothyroidism in women with early pregnancy loss.

\section{METHODS}

The study was a cross sectional study conducted in the department of obstetrics and gynaecology, Nalanda medical college and hospital from December 2017 to June 2018. One hundred and four pregnant women with early pregnancy loss (missed abortion, incomplete and complete abortion) were included in this study.

After proper written consent, 104 women were enrolled. All recruited subjects underwent a detailed history and examination as per standard pre-structured protocol. Detailed history was taken and patient's age and last menstrual period was noted. The period of gestation was calculated by last menstrual period. The demographic and clinical details were noted. Patient's menstrual history, obstetric history, past medical and surgical history and family history of thyroid disoders were also elicited in detail. A general physical examination was done. BMI was calculated based on the pre-pregnancy weight and height.

Patients with multifetal gestation, known thyroid and metabolic disorders like diabetes, hypertension, and a history of pregnancy loss were excluded from the study.

Blood samples were taken for estimation of TSH (thyroid stimulating hormone) and free T4 levels. Thyroid status of women was established on the basis of standard cut-off levels. Prevalence of hypothyroidism (both overt and subclinical) was calculated. Euthyroid women are defined as those having normal TSH $(0.1-2.5 \mu \mathrm{IU} / 1)$ in first trimester. Subclinical hypothyroidism is defined as high $\mathrm{TSH}(>3.0 \mu \mathrm{IU} / 1)$ in the presence of normal levels of Free T4 (0.8-2.0 ng/dl). Overt hypothyroidism is defined as high TSH $(>3.0 \mu \mathrm{IU} / \mathrm{l})$ with low Free T4 $(<0.8 \mathrm{ng} / \mathrm{dl})$. Subclinical hyperthyroidism is defined as low serum TSH $(<0.2 \mu \mathrm{IU} / 1)$ concentration with normal Free T4 $(0.8-2.0$ $\mathrm{ng} / \mathrm{dl})$ and overt hyperthyroidism is defined as with high Free T4 (>2.0 ng/dl) with decreased TSH $(<0.2 \mu \mathrm{IU} / \mathrm{l})$.

\section{RESULTS}

A total of 104 patients admitted in emergency department of obstetrics and gynaecology with early pregnancy loss were recruited in this study. Fifty nine women were primigravida accounting to $56.73 \%$. Forty five women were multigravida (47.26\%). The mean age of women was $22 \pm 3.4$ years $(n=104)$. The mean age of women in hypothyroid group was $24 \pm 2.3$. The mean BMI in
Euthyhroid women was $22.1 \pm 2.0$ and in hypothyroid women was $22.8 \pm 3.2$

Table 1: Comparison of age and BMI

\begin{tabular}{|c|c|c|}
\hline Comparison & $\begin{array}{l}\text { Mean age } \\
\text { (years) }\end{array}$ & $\begin{array}{l}\text { Mean BMI } \\
\left(\mathrm{kg} / \mathrm{m}^{2}\right)\end{array}$ \\
\hline Normal women & $22 \pm 3.4$ & $22.1 \pm 2.0$ \\
\hline $\begin{array}{l}\text { Hypothyroid } \\
\text { women }\end{array}$ & $24 \pm 2.3$ & $22.8 \pm 3.2$ \\
\hline
\end{tabular}

The mean TSH level was $2.3 \pm 1.3 \mu \mathrm{IU} / 1$. Twenty two women had increased TSH level $(>2.5 \mu \mathrm{IU} / \mathrm{l})$ accounting to $21.15 \%$ of total women and rest $78.84 \%$ women were euthyroid.

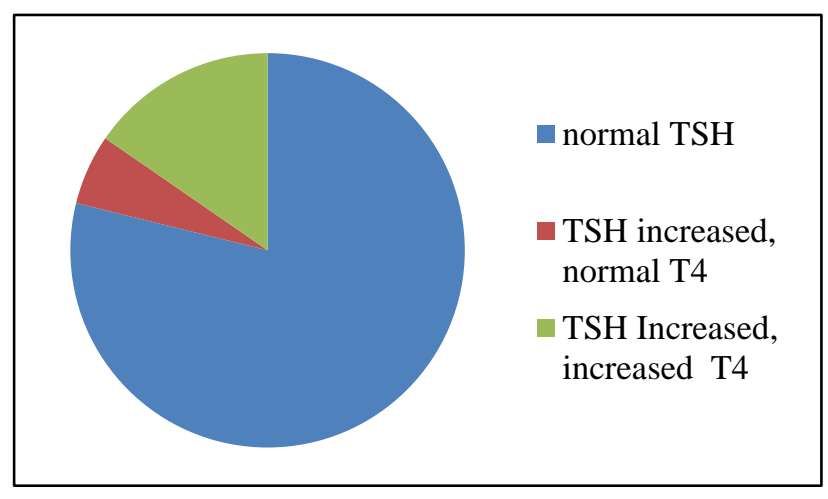

Figure 1: Distribution of women according to TSH levels.

According to Figure 1, $15.38 \%$ of women presenting with early pregnancy loss were overt hypothyroid and $5.76 \%$ of women had subclinical hypothyroidism. The mean TSH level in hypothyroid group was $4.9 \pm 2.1$. None of the women was hyperthyroid.

\section{DISCUSSION}

This study done on 104 women presenting to the emergency department in a tertiary care centre with early pregnancy loss shows that hypothyroidism is a significant cause of abortion. Twenty-two women had hypothyroidism. Abalovich et al showed that untreated hypothyroidism, subclinical or overt at the time of conception is associated with higher miscarriage rate as compared to euthyroid subjects. ${ }^{5}$ Ashoor et al demonstrated a significant association between low maternal free thyroxine (FT4) during the first trimester and fetal loss, in pregnancies complicated by subclinical hypothyroidism. ${ }^{6}$

In a retrospective cohort study done on patients with recurrent pregnancy loss the $72.7 \%$ were euthyroid (721/992), 19.4\% (192/992) were borderline-subclinical hypothyroid, and $5.4 \%$ (54/992) were sub-clinically hypothyroid $(\mathrm{SCH})$. They concluded that treatment of hypothyroidism in pregnancy should be initiated based on a TSH $>4 \mathrm{mIU} / \mathrm{l}$. Treatment initiation based on thyroid 
autoimmunity or a TSH $>2.5 \mathrm{mIU} / \mathrm{l}$ may result in overtreatment. $^{7}$

In a study done to determine the frequency of hypothyroidism in women with recurrent pregnancy loss in first trimester in the Indian population hypothyroidism was found in $4.12 \%$ women with RPL. The differences in the levels of serum T3, T4 and TSH between euthyroid and hypothyroid women were found significant in women with RPL in first trimester. ${ }^{8}$

Salek et al found that the prevalence of hypothyroidism for twin pregnancies was no higher than that for singleton pregnancies; $6.42 \%$ (7/109) vs. $5.32 \%$ (264/4965), respectively. They concluded that each first trimester screening center should establish its TSH and fT4 reference ranges. Their center had higher upper reference limits of TSH than that of the universally fixed limit of $2.5 \mathrm{mU} / \mathrm{L}$, which led to a lower measured prevalence of maternal hypothyroidism. ${ }^{9}$

A study was done by Zhang et al to evaluate the relationship between subclinical hypothyroidism $(\mathrm{SCH})$ and the risk of miscarriage before 20 weeks of pregnancy. They found that $\mathrm{SCH}$ is a risk factor for miscarriage in women before 20 weeks of pregnancy, and early treatments can reduce the miscarriage rate. Regardless of the diagnostic criteria used, the miscarriage rate increased as long as a pregnant woman was confirmed to have $\mathrm{SCH}$. In addition, $\mathrm{SCH}$ patients with thyroid autoimmunity have a higher prevalence of miscarriage, while isolated $\mathrm{SCH}$ patients also have a higher miscarriage rate than euthyroid women which is also seen in our study. They recommended early screening and treatments to avoid adverse pregnancy outcomes and complications. ${ }^{10}$

\section{CONCLUSION}

Hypothyroidism if untreated can lead to first trimester abortions. It is also a cause of recurrent abortion in Indian population. All pregnant women should be screened for thyroid disorders in their first visit and treatment should be started at the earliest.

Funding: No funding sources Conflict of interest: None declared

Ethical approval: The study was approved by the Institutional Ethics Committee

\section{REFERENCES}

1. Baek KH, Lee EJ, Kim YS. Recurrent pregnancy loss: The key potential mechanisms. Trends Mol Med.2007;13:310-7.

2. Abalovich M, Amino N, Barbour LA. Management of thyroid dysfunction during pregnancy and postpartum: an endocrine society clinical practice guideline. J Clin Endocrinol Meta. 2007;92(8):1-47.

3. Negro R, Farmoso G, Mangieri T. Levothyroxine treatment in euthyroid pregnant women with autoimmune thyroid disease: effects on obstetrical complications. J Clin Endocrinol Meta. 2006;91:2587-91.

4. So LB, Mandel SJ. Thyroid disorders during pregnancy. Endocrinol Metab Clin North Am. 2006;35:117-36.

5. Abalovich M, Gutierrez S, Alcaraz G, Maccallini G, Garcia A, Levalle O. Overt and subclinical hypothyroidism complicating pregnancy. Thyroid. 2002;12:63-6.

6. Ashoor G, Maiz N, Rotas M, Jawdat F, Nicolaides KH. Maternal thyroid function at 11 to 13 weeks of gestation and subsequent fetal death.Thyroid. 2010;20:989-93.

7. Leduc RG, Iews M, Abdelkareem AO. Prevalence of thyroid autoimmunity and effect of levothyroxine treatment in a cohort of 1064 patients with recurrent pregnancy loss. Reprod Biomed Online. 2020;40(4):582-92.

8. Rao VR, Lakshmi A, Sadhnani MD. Prevalence of hypothyroidism in recurrent pregnancy loss in first trimester. Indian J Med Sci. 2008;62(9):357-61.

9. Salek T, Dhaifalah I, Langova D, Havalova J. The prevalence of maternal hypothyroidism in first trimester screening from 11 to 14 weeks of gestation. Biomed Pap Med Fac Univ Palacky Olomouc Czech Repub. 2019;163(3):265-8.

10. Zhang Y, Wang H, Pan X, Teng W, Shan Z. Patients with subclinical hypothyroidism before 20 weeks of pregnancy have a higher risk of miscarriage: A systematic review and meta-analysis. PLoS One. 2017;12(4):e0175708.

Cite this article as: Verma P, Roy D.

Hypothyroidism and early pregnancy loss: an overview. Int J Reprod Contracept Obstet Gynecol 2020;9:5065-57. 